\title{
Inadvertent misplacement of the inferior vena cava
}

\author{
Walter V. A. Vicente ${ }^{1}$
}

Received: 24 June 2016 / Accepted: 7 December 2016 / Published online: 23 December 2016

(C) Japanese Society of Anesthesiologists 2016

To the Editor:

I congratulate Zhang et al. for reporting the inadvertent diversion of the inferior vena cava into the left atrium during a posteroinferior atrial septal defect closure [1].

Considering that this mistake has been repetitively reported over the years, in addition to the two surgical tips cited by the authors, I'd like to contribute with a simple and safe one that I teach my residents in order to avoid the aforementioned iatrogeny.

After opening the right atrium, a red flag is raised when the inferior border of the interatrial communication is flush with the inferior vena cava ostium. Under mild hypothermia $\left(34{ }^{\circ} \mathrm{C}\right)$, the surgeon, perfusionist and anesthesiologist interact, and a short period of low flow $\left(1.0 \mathrm{l} / \mathrm{min} / \mathrm{m}^{2}\right)$ perfusion is initiated. The inferior vena cava tourniquet is loosened. Venous line air embolization is prevented by the caval vein wall collapse around the cannula. Additional systemic flow reduction to around $0.5 \mathrm{l} / \mathrm{kg} / \mathrm{m}^{2}$ eliminates bleeding from the inferior vena cava. A clear exposure is obtained and the first stitches at the nadir of the patch suture line are precisely placed. The tourniquet is tightened, full flow is restored and the operation completed. I also commonly employ this maneuver to facilitate the construction of the graft-inferior caval vein anastomosis in extracardiac Fontan cases.

Yours Sincerely

Walter V. A. Vicente

Compliance with ethical standards

Conflicts of interest None.

\section{Reference}

1. Zhang Yanzi, Song Haibo, Qiao Xin, Xiao Xijun, Liu Jin, Wang Xiao. Detection and diagnosis of iatrogenic inadvertent diversion of partial inferior vena cava into the left atrium by transesophageal echocardiography during large posteroinferior surgical atrial septal defect closure. J Anesth. 2015;29:442-5.

This comment refers to the article available at doi:10.1007/ s00540-014-1925-4.

Walter V. A. Vicente

wvvicent@fmrp.usp.br

1 Division of Pediatric and Congenital Cardiovascular Surgery, Ribeirão Preto Medical School University Hospital,

University Campus, Ribeirão Preto, SP 10040-100, Brazil 